\title{
Move to be Moved
}

Kristina Höök, Martin Jonsson, Anna Ståhl, Jakob Tholander

Mobile Life @ KTH, SICS, SU

10044 Stockholm, Sweden

khook@kth.se, martinj@sh.se,

annas@sics.se, jakobth@dsv.su.se

\section{Toni Robertson}

Interaction Design and Human

Practice Lab, Faculty of

Engineering and Inf Tech

Univ of Tech Sydney

toni.robertson@uts.edu.au

\section{Patrizia Marti}

Univ of Siena \& Eindhoven Univ Via Roma 56, 53100 Siena, Italy patrizia.marti@unisi.it

pmarti@tue.nl

\section{Dag Svanæs}

Norwegian Univ. of Science and

Tech, Trondheim, Norway

dags@idi.ntnu.no

\section{Marianne Graves Peterson}

Comp Sc, Aarhus Univ., Denmark

mgraves@cs.au.dk

Jodi Forlizzi

HCI Inst, CMU, Pittsburgh, PA, US info@sietskeklooster.n!

forlizzi@cs.cmu.edu

Thecla Schiphorst

Simon-Frasier Univ, Vancouver,

British Columbia, Canada

thecla@sfu.ca

\section{Katherine Isbiste}

Comp Media, UC Santa Cruz,

Santa Cruz, CA, USA

Caroline Hummels

Sietske Klooste

Dept of Industrial Design

Eindhoven Univ, Netherlands

c.c.m.hummels@tue.nl

\section{Lian Loke}

Design Lab, Faculty of Arch., Univ

of Sydney

lian.loke@sydney.edu.au

\section{George Khut}

Faculty of Art \& Design

UNSW Australia, Sydney, Australia

george@georgekhut.com

katherine.isbister@ucsc.edu

Permission to make digital or hard copies of part or all of this work for personal or classroom use is granted without fee provided that copies are not made or distributed for profit or commercial advantage and that copies bear this notice and the full citation on the first page. Copyrights for third-party components of this work must be honored. For all other uses, contact the Owner/Author. Copyright is held by the

owner/author(s). CHI'16 Extended Abstracts, May 07-12, 2016, San Jose, CA, USA ACM 978-1-4503-4082-

3/16/05. http://dx.doi.org/10.1145/2851581.2856470

\begin{abstract}
Movement-based design is reaching critical mass in $\mathrm{HCI}$, and we can start to identify strategies, similarities and differences in how it is approached. Similarities may include, for example, a strong first person perspective on design, emphasising movement, somatics and aesthetic sensibilities of the designer, as well as starting from the premise that our bodily ways of being in the world are shaped by the ecologies of people, cultural practices and the artefacts we create and use. Different classes of systems are starting to emerge, such as spurring somaesthetic appreciation processes using biofeedback loops or carefully nudging us to interact with our own movements; engaging us in affective loops where the technology takes on a stronger agency, attempting to pull participants into particular experiences; extending on our senses and perception - even creating new senses through technology; social interactions, engaging us to jointly explore movement or touch; even endowing machines with their own 'somatics', exploring our relationship to technology; as well as engaging in larger political issues around the body, such as gender perspectives, or challenging the mind-body divide.
\end{abstract}

\section{Author Keywords}

Movement-based interaction, somaesthetic design, gender-sensitive design 


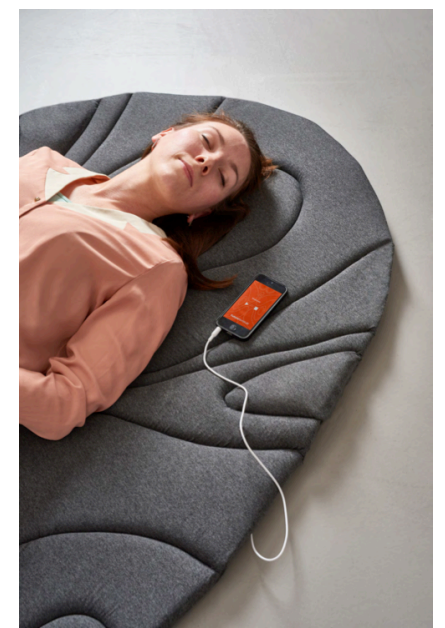

Figure 1 Soma Mat

\section{ACM Classification Keywords}

H.5.m. Information interfaces and presentation (e.g., $\mathrm{HCI}$ ): Miscellaneous

\section{Introduction: the primacy of movement}

Movement is the basis, premise and start to how we exist in the world [23]. Our perception is geared towards movement, to the extent that we cannot even see that which is not moving [ibid]. Our senses are active, not passively receiving stimuli from the environment [21]. The background to the movement is not a representation associated or linked externally with the movement itself but is immanent in the movement inspiring and sustaining it at every moment. The plunge into action is, from the subjects point of view, an original way of relating to the object, it is on the same footing as perception [ibid.] Shusterman talked about our bodies as "our indispensable tool of tools, the necessary medium of our being, perception, action and self-presentation" [24]. Our bodies hold sway of our thoughts and feelings [23] - without movement, no emotion or experience.

The idea of embodied interaction [2], has had a huge influence on HCI showing us that "you cannot separate the individual from the world in which that individual lives and acts" (p. 18) and therefore requiring that the artefacts we design must be seen as part of the whole life world of people. But in the writings about embodied interaction, the actual, corporeal body-our muscles, the way we move, our postures-has been notably absent from most of the discussion with only a few exceptions [12]. But as pointed out by SheetsJohnstone, the introduction of the term embodiment is a mere "lexical band-aid" to remedy a problem that is a fundamental misunderstanding of the human condition
[23]. As there is never any possibility for us to be disembodied, adding the concept embodied to any human activity, does not make sense. It is in our animate forms that life begins, this is where emotions are rooted, where concepts and language begins - not in something that might be termed 'mental life' according to Sheets-Johnstone. With this perspective it also becomes important to consider the impact of culture, tools and sociality on design for movement. Our bodies are "completed by culture" as expressed by Grosz [6]. Technologies take a shaping role in the ecologies of people, culture and artefacts.

\section{Design Exemplars}

Movement-based design with a specific focus on aesthetics (or somaesthetics to borrow a term from Shusterman [24] combining soma with aesthetics) is reaching critical mass and we can start to describe classes of systems with different characteristics [e.g.3,5,7,8,10,10,15,19,20,20,17,22,19,20,22,27,28] as well as important topics arising in and through this design work concerning gender, the body-mind divide and other societal discourses $[27,19]$.

For example, Khut describes his biofeedback artworks and mobile apps as engaging in audio-visual interfaces for exploring psycho-physiological self-efficacy [15]. These heart rate and brainwave controlled artworks borrow from clinical biofeedback methods in medicine, where electronic monitoring of moment-to-moment changes in a subject's physiology are fed back to the user such that they can begin to sense and eventually influence the behaviour observed. His works frame the biofeedback loop as an intensely aesthetic process of learning by doing and sensing - in which agency and self-efficacy emerge through processes of feeling into 
and feeling through the biofeedback sound and light displays.

Höök and colleagues propose Somaesthetic Appreciation Design [13] to denote a class of related systems that will carefully nudge participants into extending on their somatic awareness and even increase their mastery of their own movement and somatics, see Figure 1.

In another strand of work, Höök describes some of the work in her group as engaging users in Affective Loops [11]. These are similar to Khut's biofeedback loops, but here, the system not only mirrors users' behaviours, but also possess some agency of their own, persuading or engaging users to part-take in emotional-bodily

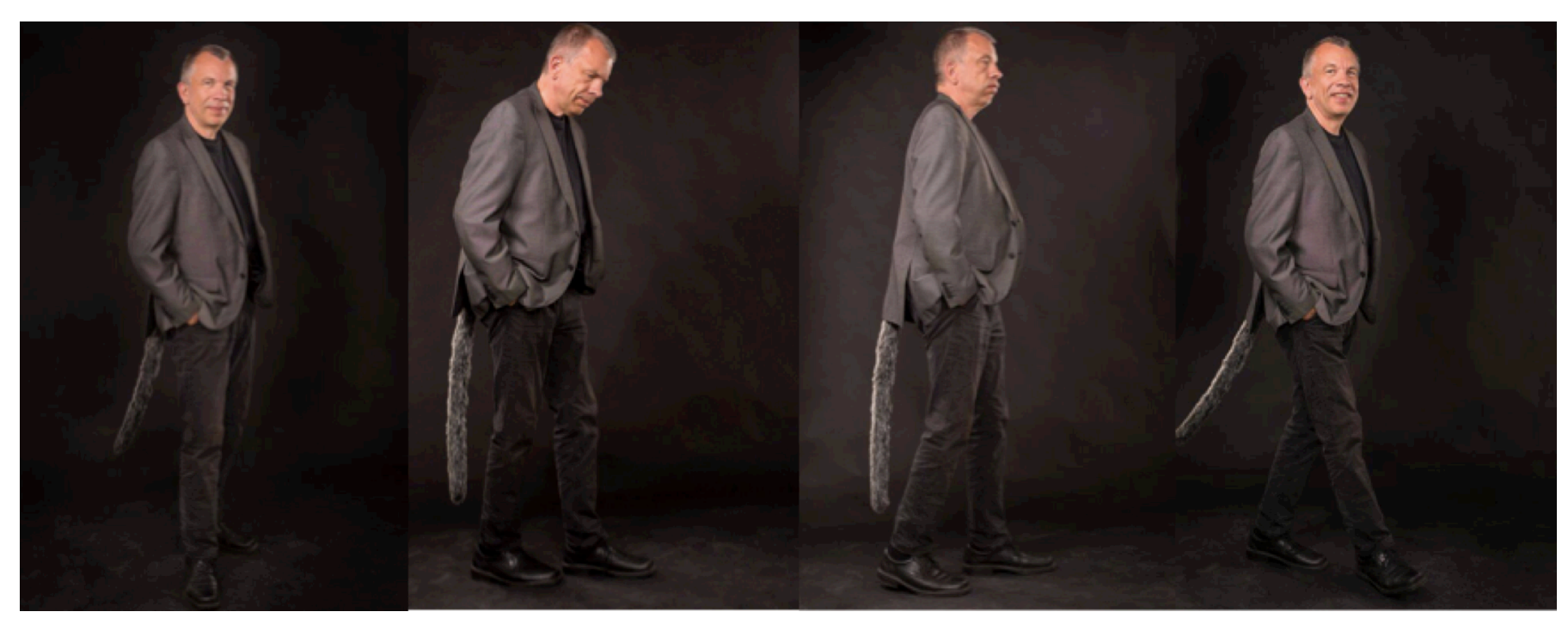

processes induced by the system.

Hobye and Löwgren frame their work on the Mediated Body as addressing Bare-Skin Connection [7]. In their Mediated Body system, two users generate and engage in a soundscape that is created when they touch oneanother's bare skin - similar to a theremin. It becomes an act of very intimate social play in public view. Schiphorst frames her work as designing for

Somaesthetic Touch [22]. The formed is closely related to Bare-Skin Connection, but is a more generic concept, engaging with touch more generally.

In social situations, these designs seem to succeed when they thrive on the empathic feel we have of others and how easily we align our expressions with others when present, in the moment $[20,14]$. Co-

Figure 2 Dag Svanaes wearing his artificial tail. 
experiencing [4], acting together, draws users into the experience unfolding together with the system. The system can serve the role as an excuse to engage in intimate interactions or a trigger of joint synchronized behaviour [12].

An interesting development lies in those interactions that are slightly scary, as in the Machine Aesthetics experience of the Metaphone [26], or Uncomfortable Interactions [1]. Both in sense rely on the computer/machine as being foreign to us, pulling us into its "somatics", its inner workings.

Somewhat tangentially, there is also work on extending our senses - adding new senses. For example, Svanaes has experimented with adding a tail to your body, connecting to your body movements, swaying in different patterns to express your emotional state, see Figure 2

\section{Move to be Moved}

This workshop at $\mathrm{CHI}$ will explore the design landscape in formation, with a particular focus on a body- and movement-based aesthetically-inspired, first-person perspectives on interaction design. We will discuss how the ecologies of people, cultural practices and design exemplars alter and extend on our ways of being in the world - how we are shaped by and shape the technologies surrounding our bodies. We will also debate larger political issues around the body, such as gender perspectives, or challenging the mind-body divide.

The overall goal of the workshop is to start forming a proper academic community within $\mathrm{HCI}$ and $\mathrm{IxD}$, where ideas, designs and bodily experiences can be discussed and shaped, moving our topic forward.

\section{Workshop proposers}

The workshop is proposed by an international team of researchers from the Sweden, Australia, The

Netherlands, US, Norway, Denmark, Italy and Canada:

Professor Kristina Höök, KTH, manages the Mobile Life centre, a design-driven 10-year research program. Her research focus is on designing for somaesthetics, emotion and sociality. She recently wrote a cover paper for interactions on somaesthetic design.

Associate Professor Martin Jonsson is a senior researcher at the Mobile Life centre and Södertörns University. His research focuses on embodied and tangible interaction, exploring aspects from interaction design for children to materiality in making to somaesthetic design.

Dr. Anna Ståhl, SICS, is a senior researcher at the Mobile Life centre. She has a background in industrial design. Her current research focus is on designing for somaesthetics, emotions, and how to fill the gap from abstract theory into design practice.

Associate Professor Jakob Tholander is a senior researcher at the Mobile Life centre and Stockholm University. His current research focuses on interactive technologies for movement in sports. He recently edited a special section in SIGCHI interactions magazine on interaction design and sports.

Professor Toni Robertson co-directs the Interaction Design and Human Practice Lab (IDHuP) at the 
University of Technology Sydney. Her research is directed towards principled and generative groundings for the design and evaluation of technologies that privilege the experience of those who use the technology and advance human agency in all aspects of technology design and use.

Professor Patrizia Marti manages the Laboratory of Robotic and Learning Technologies at the University of Siena. Her research activity concerns designing systems facing cultural, aesthetic and social issues through embodied experiences. In 2014 she gave her inaugural lecture at the Eindhoven University of Technology on the role of the body and movement in interaction from a phenomenological perspective.

Professor Dag Svanæs manages the Health Technology Usability Lab at NTNU. His main research interest is on interaction design for the body. Since the 1990s he has been using the phenomenology of Merleau-Ponty as a theoretical framing for understanding the bodily aspects of the user experience.

Associate Professor Marianne Graves-Petersen at Aarhus University in Denmark, early on worked on pragmatism and somaesthetics as an inspiration for design. Also works with shape-changing interfaces.

Professor Jodi Forlizzi works at the Human-Computer Interaction Institute and the School of Design at CMU. Her research ranges from understanding the limits of human attention to understanding how products and services evoke social behavior, designing and research systems ranging from peripheral displays to social and assistive robots and interfaces to control them.
Thecla Schiphorst is Associate Director and Associate Professor in the School of Interactive Arts and Technology at Simon Frasier University in Vancouver, Canada. Her background in dance and computing form the basis for her research in embodied interaction, focusing on movement knowledge representation, tangible and wearable technologies, media and digital art, and the aesthetics of interaction.

Professor Caroline Hummels is heading the Designing Quality in Interaction group at the department of Industrial Design (ID) at the Eindhoven University of Technology (TU/e). She designs for transformative qualities grounded in embodiment, inspired by multiple fields of knowledge, such as phenomenology of perception, Gibson's ecological theory of perception, social situatedness and embodied cognition.

Sietske Klooster is independant designer and part of the Designing Quality in Interaction (DQI) group at the TU/e. She started to work on movement based design during her graduation project 'design moves' in 2002 and hereafter started to work on Choreography of Interaction at DQI. Embodied design for socio-cultural transformation became her main focus. Currently she runs a project on sustainable transformation in the Dutch culture of dairy.

Katherine Isbister is Professor of Computational Media at the University of California, Santa Cruz, where she directs the Social and Emotional Technology Lab. Her group builds and studies movement-based games that push the boundaries of sensor-based interaction with systems. 
Dr George (Poonkhin) Khut is an artist and interactiondesigner at the University of New South Wales (UNSW), Australia. His body-focussed interactive and participatory artworks use biosensing technologies to re-frame experiences of self, embodiment, health and subjectivity.

Dr Lian Loke has an established research program of working with somatic practitioners and dancers to inform the design and human experience of bodyfocused interactive systems.

\section{Workshop website}

http://mobilelifecentre.org/node/1671

\section{Workshop Organisation}

\section{Before the workshop}

The workshop is aimed at for HCI and interaction design researchers with an interest in designing interactions based on movement or technologies on or around the body.

The participants will be a mixture of specific invitations to some of the key researchers in this area. There will also be an open invitation from which we select participants based on short position statements, 2 pages maximum, outlining their interests in this topic.

Participants will be recruited through research networks such as CHI-ANNOUNCEMENTS@LISTSERV.ACM.ORG as well as 'local' lists such as the PhD Design mail list, NordiCHi, Nordes, DRS, etc.

We will create and continuously update a website for the workshop. We will solicit input to the website (e.g. blog posts communicating key positions) from participants and integrate social media channels to raise awareness of the workshop and prompt interaction between participants.

\section{During the workshop}

The format of the workshop will be divided into three different activities. After a quick speed-dating exercise where everyone gets to know everybody else, the first activity (both days) will be a practical, body-based interaction, possibly making use of some of the technologies designed by the participants. We wil encourage workshop participants to bring designs (when possible) that we together probe, test and discuss.

This part of the workshop requires space enough for everyone to move, perhaps lie on the floor on yogamats. The second part will be more of a traditional workshop presentation round where the participants provide brief statements of their design and research position, their latest work and what they see as important topics on an agenda for the future. The third will be a brainstorming activity to collect an agenda for continued Move to be Moved activities (such as expanding the workshop into a workshop series? Or even a conference? Create our own CHI community?) and joint research explorations for the future.

After the workshop

The workshop organizers will actively seek to publish a piece in interactions and possible follow up with another workshop or conference if the interest is deemed substantial enough. Our aim is to start building a community sharing an interest in aesthetically-inspired movement-based interactive designs. 


\section{Call for Participation}

Movement-based design is reaching critical mass in $\mathrm{HCI}$, and we can start to identify strategies, similarities and differences in how it is approached. Similarities may include, for example, a strong first person perspective on design, emphasising movement, somatics and aesthetic sensibilities of the designer, as well as starting from the premise that our bodily ways of being in the world are shaped by the ecologies of people, cultural practices and the artefacts we create and use. The workshop will discuss similarities and differences between specific design exemplars; ways of extending on our senses and perception - even creating new senses through technology; social interactions, engaging us to jointly explore movement or touch; endowing machines with their own 'somatics'; as well as engaging in larger political issues around the body, such as gender perspectives, or challenging the mind-body divide.

\section{References}

1. Steve Benford, Chris Greenhalgh, Gabriella Giannachi, Brendan Walker, Joe Marshall, and Tom Rodden. 2012. Uncomfortable interactions. In Proc of the SIGCHI Conf on Human Factors in Computing Systems (CHI '12). ACM.

2. Paul Dourish. 2004. Where the action is: the foundations of embodied interaction. The MIT Press.

3. Frank Feltham, Lian Loke, Elise van den Hoven, Jeffrey Hannam, and Bert Bongers. 2014. The slow floor: increasing creative agency while walking on an interactive surface. In Proc of the 8th Intern. Conf on Tangible, Embedded and Embodied Interaction (TEI '14).

4. Jodi Forlizzi and Katja Battarbee. 2004. Understanding experience in interactive systems. In Proc of the 5th conf on Designing interactive
The format of the workshop is divided into three activities: first a practical, body-based interaction, second a presentation round where the participants provide brief statements of their design and research position, their latest work and what they see as important topics on an agenda for the future, and third a brainstorming activity to collect an agenda for continued Move to be Moved activities and joint research explorations for the future.

To participate, please submit a 2-page position statement to the workshop organiser, Kristina Höök, khook@kth.se. If accepted, at least one of the authors has to attend the workshop and register for at least one day of the $\mathrm{CHI}$-conference.

systems: processes, practices, methods, and techniques (DIS '04). ACM.

5. Marianne Graves Petersen, Ole Sejer Iversen, Peter Gall Krogh, and Martin Ludvigsen. 2004. Aesthetic interaction: a pragmatist's aesthetics of interactive systems. In Proc of the 5th conf on Designing interactive systems: processes, practices, methods, and techniques (DIS '04). ACM.

6. Elizabeth Grosz. 1994. Volatile Bodies: Toward a corporeal feminism, Indiana University Press.

7. Mads Hobye and Jonas Löwgren. 2011. Touching a stranger: Designing for engaging experience in embodied interaction. Int. J. Design 5(3):31-48.

8. Caroline, Hummels, Kees Overbeeke, and Sietske Klooster. 2007. Move to get moved: a search for methods, tools and knowledge to design for expressive and rich movement-based interaction. Pers. and Ubiquitous Computing, 11(8), 677-690. 
9. Caroline Hummels and Jelle van Dijk. 2015. Seven principles to design for embodied sensemaking. In TEI '15 Proceedings (pp. 21-28). New York: ACM.

10. Hoffman, Guy, and Wendy Ju. Designing Robots With Movement in Mind. Journal of Human-Robot Interaction 3.1 (2014): 89-122.

11. Kristina Höök. 2008. Affective Loop Experiences What Are They?. In Proc of the 3rd international conf on Persuasive Technology (PERSUASIVE '08), Oinas-Kukkonen et al. (Eds.). Springer-Verlag, Berlin, Heidelberg, 1-12.

12. Kristina Höök. 2010. Transferring qualities from horseback riding to design. In Proc of the 6th Nordic Conf on HCI (NordiCHI'10). ACM.

13. Kristina Höök, Anna Ståhl, Martin Jonsson, Johanna Mercurio, Anna Karlsson, and Eva-Carin Banka Johnson. 2015. COVER STORY: Somaesthetic design. interactions 22, 4 (June 2015), 26-33.

14. Isbister, K. (2011). Emotion and Motion: Games as Inspiration for Shaping the Future of Interface. Interactions, September/October 2011

15. Khut, G. (2006). Development and Evaluation of Participant-Centred Biofeedback Artworks. Unpublished doctoral exegesis, University of Western Sydney.

16. Lee, W., Lim, Y. K., \& Shusterman, R. (2014, June). Practicing somaesthetics: exploring its impact on interactive product design ideation. In Proc of the 2014 conf DIS. ACM.

17. Loke, L., Khut, G., Muller, L., Slattery, M., Truman, C. and Duckworth, J. (2013) Re-sensitising the body: Interactive art and the Feldenkrais Method. International Journal of Arts and Technology.

18. Loke, L. and Robertson, T. (2013) Moving and Making Strange: An Embodied Approach to Movement-based Interaction Design. ACM Trans. Comput.-Hum. Interact. 20, 1, Article 7 (March 2013).
19. Patrizia Marti. 2014. The Subtle Body. Eindhoven Technical University Library, ISBN: 978-90-3863714-3.

20. Helena M. Mentis, Jarmo Laaksolahti, and Kristina Höök. 2014. My Self and You: Tension in Bodily Sharing of Experience. ACM Trans. Comput.-Hum. Interact. 21, 4, Article 20.

21. Maurice Merleau-Ponty. 1962. Phenomenology of perception. Routledge.

22. Thecla Schiphorst. 2009. Soft (n): Toward a somaesthetics of touch. In $\mathrm{CHI}^{\prime} 09$ Extended Abstracts on Human Factors in Computing Systems (pp. 2427-2438). ACM.

23. Maxine Sheets-Johnstone. 2011. The primacy of movement (Vol. 82). John Benjamins Publishing.

24. Richard Shusterman. 2008. Body consciousness: $A$ philosophy of mindfulness and somaesthetics. Cambridge University Press.

25. Richard Shusterman. 2013. Somaesthetics. The Encyclopedia of Human-Computer Interaction, 2nd Ed. Soegaard, Mads, and Rikke Friis Dam.

26. Vygandas Šimbelis, Anders Lundström, Kristina Höök, Jordi Solsona, \& Vincent Lewandowski. 2014 Metaphone: machine aesthetics meets interaction design. In Proc of the SIGCHI Conf on Human Factors in Computing Systems (pp. 1-10). ACM.

27. Dag Svanæs, 2013. Interaction design for and with the lived body: Some implications of MerleauPonty's phenomenology. ACM Trans. on ComputerHuman Interaction (TOCHI), 20(1), 8.

28. Jay Vidyarthi, Bernhard E. Riecke, and Diane Gromala. 2012. Sonic Cradle: designing for an immersive experience of meditation by connecting respiration to music. In Proc of the Designing Interactive Systems Conf (DIS '12). ACM. 